\title{
Public Service Announcements for Health Insurance in Nepal: Perspectives from Health Belief Model
}

\author{
Devaraj Acharya $^{1 *}$, Bhimsen Devkota ${ }^{2}$, Radha Bhattarai ${ }^{1}$ \\ ${ }^{1}$ Bhairahawa Multiple Campus, Rupandehi. \\ ${ }^{2}$ Mahendra Ratna Campus, Tahachal, Kathmandu. \\ *Corresponding email:drabmc@gmail.com
}

\begin{abstract}
Public Service Announcement (PSA) is an advertisement to inform the people sponsored by the public company or the governmental agencies. There were several PSAs implemented to inform the people about health insurance (HI). Data from the Health Insurance Board showed low enrolment with high dropout in health insurance programme (HIP). It was found that the PSAs could not attract the people. Therefore, we assessed the PSAs used for the HIP and amomg them, three Radio/FM jingles, eight TV spots, hoarding board, newspapers, and brochure were evaluated using the Health Belief Model (HBM). We found the almost all PSAs have not covered the constructs of HBM. Most of the PSAs have included primarily perceived benefits and perceived susceptibility but missed to include perceived severity, perceived threats, and self-efficacy. Only benefits focused message could not attract the people. Therefore, we recommend that all PSAs need to have all the features of HBM in the PSA messages while notifying and informing the people.
\end{abstract}

Keywords: Advertisement; health information; health insurance; mass media and communication; public awareness; Public Service Announcement

\section{Background}

The Government of Nepal [GoN] initiated health insurance programme [HIP] as social health security in three districts: Kailali, Baglung and Ilam in 2016. The HIP is novel for Nepalese people (Health Insurance Board, 2019). Most people did not have adequate 
Volume 3 Issue $3 \quad$ Dec $2020 \quad 2565-4942$ (Print) 2738-9693 (online)

knowledge about health insurance [HI]. In such a context, people may not participate in the programme. Access to accurate, sufficient and timely information is vital for healthrelated decision making (Kreps et al., 2017). However, just before the implementation of the HIP in 2014, 11 percent of the people had heard about HI and only one out of ten (9\%) had good knowledge about it (KOICA-Nepal Health Insurance Support Project [NHISP], 2014). Access to mass media is one of the best means to disseminate healthrelated information to the mass population. Data show the diverge observation in access to mass media at a different time as well as place. Nine out of ten $(89.5 \%)$ knew community-based health insurance [CBHI] programme among the members who had taken membership of CBHI compared to three-fourth [75.7\%] of those who had no membership card of CBHI in Sunsari District (Subedi et al., 2018).

Nepal Demographic and Health Surveys [NDHS] show the different trend of access to mass media to age 15-49 years of men and women over the survey years. Of the media, 15-49 years, 31.4, 34.2, and 27.7 percent of them had access to the newspaper at least once a week in the survey year 2006, 2011, and 2016 respectively compared to $10.3,12.6$, and 8.7 percent of women of reproductive age [15-49] had access to newspaper respectively at least a week in the corresponding years. But access to TV noticed as in increasing trends. Near to half (44.9\%), 54.7, and 51 percent men of age 15-49 had access to TV compared to women (15-49 years) 38.1 , 47.4, 50.3 percent respectively in NDHSs 2006, 2011, and 2016. Interestingly, access to Radio observed as in decreasing trends. More than three-fourth (77.7\%), 58.5, and 36.1 percent of the men had access to Radio compared to $60.5,44.2$, and 27.7 percent of the women respectively in the respective NDHSs 2006, 2011, and 2016. Access to all these media (Newspaper, TV, and Radio) was in decreasing trends (in men: 22.2\%, 20.1\%, 9.4\% and in women 8.0 \%,7.4\%, 3.2\%) while access to none of these media was in increasing trends (in men 16.5\%, 19.5\%, 31\% and in women 30\%, 33\%, 37.2\%) respectively in NDHSs 2006, 2011, and 2016 (Ministry of Health et al., 2017; Ministry of Health and Population (MOHP) [Nepal] et al., 2007, 2012). Latest NDHS showed that 29 percent of household heads had Radio, and 52 percent had a TV in 2016/17 (Ministry of Health et al., 2017).

The GoN initiated HI programme in three districts in 2016 (Health Insurance Board, 2019) in initial phase without proper homework. Many people were unaware of HI and its working structure (Acharya et al., 2019; KOICA-Nepal Health Insurance Support Project [NHISP], 2014). Data from Health Insurance Board [HIB] shows that enrollment in HI seemed low with low renewal rates thought people want to pay more than two folds higher than the contribution amount (Acharya et al., 2018). It may be the cause of inadequate knowledge and low satisfaction from HI programme and its functioning mechanism. Various factors associated with HI (Acharya, 2020); however, interaction with peers and neighbours appeared to influence enrollment (Acharya et al., 2020).

There is a mandatory provision to enrol in HI (Health Insurance Act, 2017) after the formulation of the Health Insurance Act in 2017. Consequently, HI regulation is under the implementation phase (Health Insurance Act, 2017; Health Insurance Regulations, 2075, 2019). By the end of 2019, 18 percent of the total household were enrolled in the 
programme implemented districts, whereas just eight percent in national level (Health Insurance Board, 2020). The HIP has now covered 55 districts, 505 local bodies and $26,87,810$ populations were enrolled by the end of Falgun 2076 BS (Ministry of Finance, 2020, p. 159). After seeing these facts, it can be concluded that there might be two kinds of drawbacks. First, quality services to the enrolled members and another might be the lack of accurate, adequate and timely information about $\mathrm{HI}$ and its working nature.

\section{Literature Review}

Public Service Announcement (PSA) is a kind of advertisement to inform or attract the people sponsored by governmental institutions or any other agencies (Murry et al., 1996). A new programme needs an adequate information to the general public for sensitization, consciousness, and motivation. Various benefits packages are being offered by various private and public health service providers, including health insurance companies. PSAs are mostly used to attract and inform people. Researchers indicated the various PSA activities could influence audiences' health related knowledge, perception and attitude. It should be evaluated whether it is audience-centred or not (Hoffman et al., 2020).

PSAs consist of a simple but memorable message to persuade, inform or motivate people for healthy behaviours that are usually less than one minute trying to reach larger audiences (Borzekowski \& Poussaint, 1999). A study from Indonesia showed that PSA appeared a useful tool for conveying the message to the public about stunting related information such as definition, indicators and risk factors (Liem et al., 2019). PSA can be developed mainly for two purposes: first developing a positive attitude towards the programmes or products and creating a negative attitude for unhealthy behaviour such as anti-smoking attitudes (Rydell et al., 2013). Interestingly, information spreads very fast, whether it is good (true) or bad (false) (Maidin et al., 2019).

A study from Minneapolis, Chicago, USA showed a significant association between teenagers' characteristics and perception of anti-violence-related PSAs. It found a weak relationship (Borzekowski \& Poussaint, 1999). Similarly, another study explored that higher exposure to health insurance-related media messages was significantly associated with the uninsured rate. A web-based intervention for anti-smoking behaviour was positively influenced to reduce smoking behaviour (Macy et al., 2015). Therefore, PSA is useful to change the desired behaviour.

\subsection{Theoretical Base}

This paper's theoretical base is the Health Belief Model [HBM] developed by Hochbaun in 1958. The main spirit of the HBM is if people perceived themselves as susceptible to diseases or health problems and believed the health condition would become a severe circumstance physically or financially. If they perceived a definite course of action would overcome or reduce the problem and the action(s) feasible to them in cost and other settings, they would be more likely to take action (Champion \& Skinner, 2008). In the context of PSA for HI, upon the basis of HBM, all PSA related messages need to be considered the constructs of HBM while developing it. 
Many studies conducted in the issues of determinants of enrollment in HI, willingness to pay for HI but study about PSA and HI seem scarce. It is still unanswered whether the PSA disseminated to the people is adequate, accurate, or per the household's need. Therefore, the study aimed to assess the PSA implemented by the Social Health Security Development Committee (SHSDC) and Health Insurance Board (HIB) before 2018 from the perspective of HBM.

\section{Methodology}

The article is based on the secondary sources, i.e. public services announcements such as radio/FM, television, hoarding board, newspapers, and poster/pamphlet for public interests about HI. Several media were broadcast or published by HIB (formerly SHSDC) to inform or to make aware of the public. Some of the radio jingles, TV spots, and Hoarding board messages are selected for evaluation from behaviour change with references to HBM. The HBM guides the article. Therefore, results and discussions are deliberated from the behaviour change perspective. Radio jingles, TV spots, messages of $\mathrm{HB}$, and messages on poster, pamphlet or flyer were assessed with references to primary constructs of HBM such as perceived susceptibility, perceived severity, perceived threats and benefits, and self-efficacy. All together three radio jingles, eight television messages, hoarding boards, newspapers, and poster/pamphlets were assessed from the perspectives of HBM.

\section{Results and Discussion}

There were various messages broadcast from Radio/FM and TV. Similarly, some messages were disseminated by Hoarding Boards, Newspapers, Flyers and others. In this paper, three Radio jingles, eight TV spots and messagtes from Hoarding Boards, Newspapers, Flyers were assessed.

\subsection{Radio/FM Jingles}

There were various Radio jingles about $\mathrm{HI}$ for public interest however three Radio jingles are assessed here concerning HBM.

\subsubsection{Save seven rupees every day....[Harekdin Saat Rupaiya].. as the song}

Saving 7 rupees a day

Health Insurance covers for a 5-member family is a way

Let's do Health insurance for assuring up to one year, so why do they become worried that limits 50 thousand.

Let's enrol in Health insurance and stay assured. Let's enrol in Health insurance and stay secured.

Stay assured you and your families, reduce health treatment cost by enrolling health insurance implemented by Government of Nepal, Social Health Insurance Development Committee.

(Acharya, 2020, p., 255). 
In this jingle, the massage only focuses on the benefits of the enrolment. It could not emphasize the severity and susceptibility of illness or health problems. In the same way, the message remains silent about the perceived threat as well as self-efficacy. From the perspective of HBM the message could not cover the constructs of HBM [Table 1].

\section{1.2 Disease and illness never inform....[Rog Bimar Upathero]...as a song}

Disease and illness never inform before happening.

No one left even child, adult, any age

Mountain, Hill, Terai! Let's assure all by enrolling health insurance.

After saving 7 rupees every day, it will be enough for a 5-member family for a year. Health insurance bears the treatment cost up to 50,000.

(Acharya, 2020, p. 255)

In this jingle, the massage appears more progressive than the previous one. The jingle covers the susceptibility of illness or health problems and the benefits of the enrolment. It could not emphasize the severity/threat of illness or health problems as a whole. In the same way, the message remains silent about the perceived threat as well as self-efficacy. From the perspective of HBM, the message could not cover the constructs of HBM [Table 1].

Table 1

Appraisal of PSA based on HBM

\begin{tabular}{|c|c|c|c|c|c|c|}
\hline \multirow[b]{2}{*}{ Message name } & \multicolumn{5}{|c|}{ Components of the Health Belief Model } & \multirow[b]{2}{*}{ Remark* } \\
\hline & $\begin{array}{c}\text { Perceived } \\
\text { susceptibility }\end{array}$ & $\begin{array}{l}\text { Perceived } \\
\text { severity }\end{array}$ & $\begin{array}{c}\text { Perceived } \\
\text { threat }\end{array}$ & $\begin{array}{l}\text { Perceived } \\
\text { benefits }\end{array}$ & $\begin{array}{l}\text { Self- } \\
\text { efficacy }\end{array}$ & \\
\hline $\begin{array}{l}\text { Radio: Save } \\
\text { seven.... }\end{array}$ & & & & $\sqrt{ }$ & & A aid \\
\hline $\begin{array}{l}\text { Radio: Diseases and } \\
\text { illness... }\end{array}$ & $\sqrt{ }$ & & & $\sqrt{ }$ & & $A$ aid \\
\hline $\begin{array}{l}\text { Radio: Greetings } \\
\text { uncle... }\end{array}$ & & & & $\sqrt{ }$ & & A aid \\
\hline $\begin{array}{l}\text { TV: Rajesh } \\
\text { Hamal. }\end{array}$ & & & & $\sqrt{ }$ & & AV aid \\
\hline TV: Yamraj. & & & & $\sqrt{ }$ & & AV aid \\
\hline $\begin{array}{l}\text { TV: Suntali } \\
\text { Dhurmus }\end{array}$ & $\sqrt{ }$ & $\sqrt{ }$ & & $\sqrt{ }$ & $\sqrt{ }$ & AV aid \\
\hline TV: Jigri, Pande & & & & $\sqrt{ }$ & & AV aid \\
\hline TV: Dr Koirala & $\sqrt{ }$ & $\sqrt{ }$ & $\sqrt{ }$ & $\sqrt{ }$ & & AV aid \\
\hline TV: Aboard call & $\sqrt{ }$ & & & $\sqrt{ }$ & & AV aid \\
\hline $\begin{array}{l}\text { TV: Pashupati } \\
\text { song }\end{array}$ & $\sqrt{ }$ & & & $\sqrt{ }$ & $\sqrt{ }$ & AV aid \\
\hline TV: Spouse talks & & & & $\sqrt{ }$ & & AV aid \\
\hline Hoarding Boards & $\sqrt{ }$ & & & $\sqrt{ }$ & $\sqrt{ }$ & $\mathrm{V}$ aid \\
\hline
\end{tabular}




\begin{tabular}{lccc}
\hline Newspapers & $\sqrt{ }$ & $\sqrt{ }$ & V aid \\
\hline $\begin{array}{l}\text { Guidelines, } \\
\text { Brochure }\end{array}$ & $\sqrt{ }$ & $\sqrt{ }$ & V aid \\
\hline
\end{tabular}

Note: $* \mathrm{AV}=$ Audio and Visual, $\mathrm{V}=\mathrm{V}$ isual, and $\mathrm{A}=$ Audio(Acharya, 2020, p. 73)

\section{1.3 Greetings Uncle.... [Namaskar Kaka]....as a conversation}

Namaskar Uncle! You are in so-hurry! What happened?

Namaskar niece! The daughter became sick, suddenly and we have no money to go to the hospital. I am moving to beg debt.

Oh! How much you need? I have 2-3 thousand.

That's sufficient. Niece!

Uncle! Is this obtainable way to beg debt?

What can I do, niece? As we are poor.

Uncle! After enrolling in health insurance, no need to move for begging debt for treatment.

I could not understand you, niece?

After enrolling in health insurance by paying 2500 rupees, it covers up to 50,000 rupees' treatment cost for you and your family every year. Enrollment assistants visit door to door for it.

Oh, niece! Then, our family will become a member of health insurance shortly.

Let's participate in health insurance. Let's be assured you and your family for treatment.

(Acharya, 2020, pp. 255-256)

In this jingle, the massage only focuses on the benefits of the enrolment. It could not emphasize the severity, susceptibility, and threats of illness or health problems. In the same way, the message could not include perceived threat as well as self-efficacy. From the perspective of HBM the message could not cover the constructs of HBM [Table 1].

\subsection{TV Spots}

There were various TV spots broadcasted from different TV channels about HI for public interest however eight TV spots were assessed here concerning HBM.

\subsubsection{TV Spot: Rajesh Hamal}

The message had included mostly benefits of enrollment in the insurance in a perspective of financial benefits. The message could not include other aspects of HBM [Table 1]. Therefore, the message is observed as an ineffective PSA from the perspective of HBM. Please find the link for message details at Appendix I. 


\subsubsection{TV Spot: Yamraj}

The message has also included the benefits of enrolment from the perspective of finance. All other constructs of HBM are missed [Table 1]. Therefore, the message can be considered as defective in terms of HBM constructs. Details of the message can be obtained from the link presented in Appendix I.

\subsubsection{TV Spot: Suntali-Dhurmus}

The message is comparatively more progressive than previous messages from the perspective of HBM. The message has included nearly all constructs of HBM [Table 1]. Mainly perceived susceptibility, severity, benefits and self-efficacy are included in this message. The TV spot id also long in terms of time than others. Please see the link in Appendix I.

\subsubsection{TV Spot: Jigri-Pande}

The message included mostly benefits of enrollment in the insurance that means from a financial perspective only. The message could not include other aspects of HBM [Table 1]. Therefore, the message is noticed as an ineffective PSA from the perspective of HBM. Please find the link for message details at Appendix I.

\subsubsection{TV Spot: Dr Koirala}

This was the most attractive message among the TV spots. Nearly all aspects of HBM were included in this advertisement. The primary constructs of HBM: perceived susceptibility, perceived severity, perceived threats, perceived benefits were included in the spot [Table 1]. Therefore, this message can be considered one of the most attractive TV spots from the perspective of HBM. Details of the message can be run from the link presented in Appendix I.

\subsubsection{TV Spot: Mother-son talking from aboard}

This message was a conversation between mother and son from aboard. The message has mainly focused on the perceived susceptibility and benefits of the HI concerning HBM. Primarily, two major constructs of the HBM was included in the message [Table 1]. Details of the message can be watched from the YouTube link (Appendix I)

\subsubsection{TV Spot: Pashupati-song}

The message was a song and funny to watch; however, only three primary constructs of HBM, i.e. perceived susceptibility, perceived benefits and support to self-efficacy [Table 1]. Comparatively the message is more attractive comparative another TV spot though it is not enough from the viewpoint of HBM. The message can be observed from the link obtainable in Appendix I.

\subsubsection{TV Spot: Spouse-talking}

The message has also included the benefits of enrolment from the perspective of finance. All other constructs of HBM were missed [Table 1]. Therefore, the message can be 
considered as defective from the angle of HBM constructs. Details of the message can be obtained from the link presented in Appendix I.

\subsection{Hoarding Boards}

Most of the hoarding boards [HB] were placed at the service point that means in the health facility and at the entry point of the districts where the programme implemented. Most of the HB included the message of the benefits of enrolment [Table 1]. In some HBs there was message related to perceived susceptibility and support to self-efficacy message. From the perspective of HBM, it is not enough since the HB contained only two to three constructs of HBM [Figure 1].
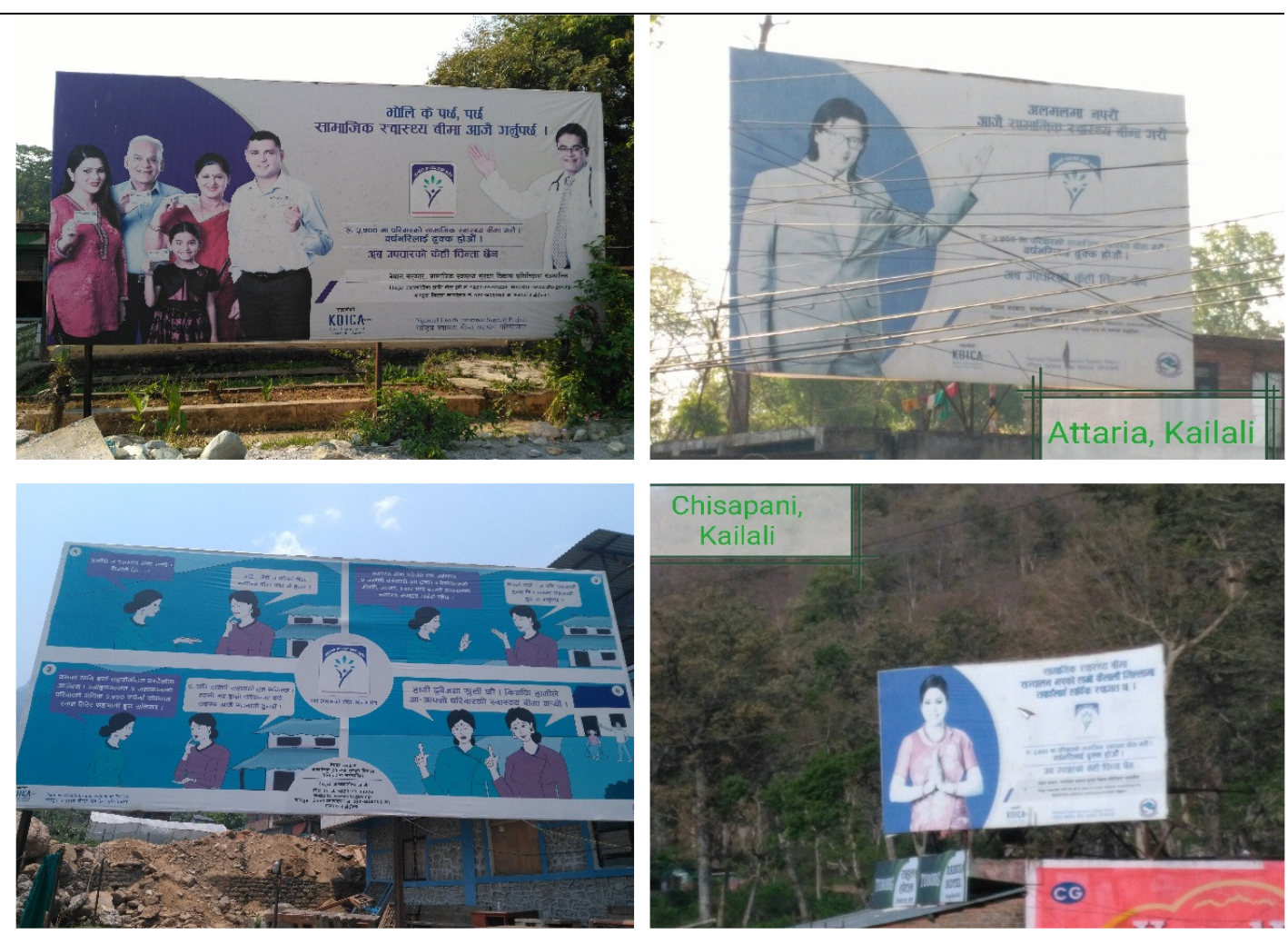

Figure 1: Hoarding board for health insurance-related messages

\subsection{Newspaper}

Newspaper is one of the most critical media for health communication. According to Economic Survey 2077, there were 7801 Newspapers published daily, weekly, monthly or yearly throughout the country (Ministry of Finance, 2020). Frequently HI related messages and articles are being published in the newspaper, and some are advertisements. Considering the published PSA associated with HI, most of the messages are benefitsfocused. They have only included messages related to perceived susceptibility and perceived benefits [Figure 2]. 


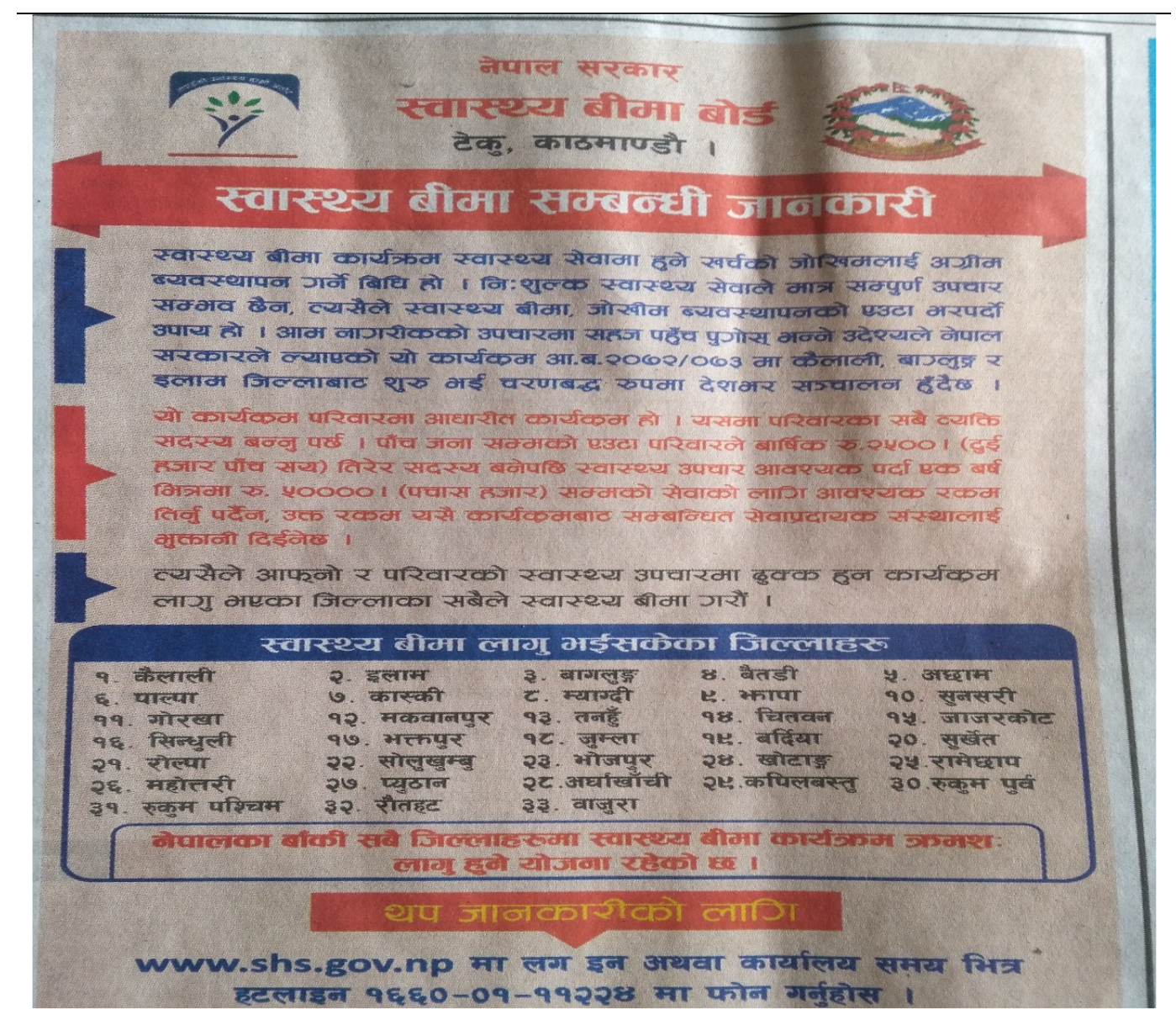

Figure 2: Newspaper for health insurance-related message

\subsection{Guidelines/Brochure}

The guidelines and brochure were also informative, that includes perceived susceptibility and perceived benefits related messages. They missed informing about perceived severity, perceived threats and support for self-efficacy [Figure 3]. In the same way guidelines for HI were also just information and focused on HI programme benefits.

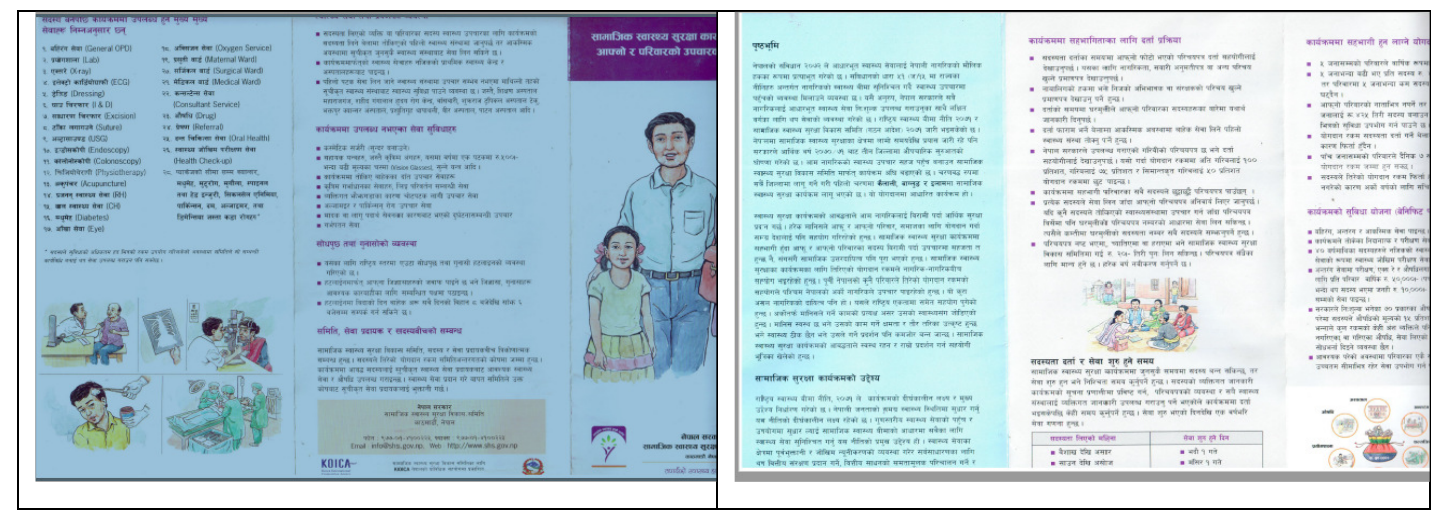

Figure 3: Brochure for health insurance-related message

\section{Disucssion}


After assessing all the PSA tools, it can be concluded that these PSA tools need to be reconstruct since they could not meet the constructs of HBM. A study conducted in Baglung and Kailali in 2018 showed that perceived susceptibility, perceived severity, perceived threats, and perceived benefits were significantly associated with HI's enrolment. However, most of the advertisement (PSA) were not maintained as per the theoretical base of HBM.

A study from South Korea showed that establishing a structured educational programme (PSA) could lead to better participation in National Health Insurance Service (Lee et al., 2019). Similarly, Nan explored that PSA could influence the individual with a strong and positive attitude (Nan, 2008). Therefore, an appropriate PSA would be one of the main determinants for enrollment in HI. The first-hand message from PSA was found effective for organ donation (White \& Dillon, 2000) that can be translated in HI. However, the PSA's credibility mostly depends on expertise and trustworthiness, so these factors should be considered while disseminating it (Toncar et al., 2007).

PSA was tested in different fields and mostly found it useful to change the behaviour. A PSA for anti-marijuana, using TV messages, was noticed as applicable as per the theory of the elaboration likelihood model (Weber et al., 2013). A PSA campaign meaningfully addressed the drug prevention perception among youth vulnerable in Vancouver, Canada (Ti et al., 2017). Similarly, an anti-smoking PSA was found effective to change the negative attitude towards smoking (Won et al., 2017). Likewise, a PSA was also an effective strategy to improve the knowledge and attitude of HPV and its vaccine (Kepka et al., 2011).

A PSA for the eye-care programme was found compelling, and it encouraged people to have an eye examination. The study further indicated the young age, female, diabetic patients, un-insured and proximal distance were associated with eye examination (Hoffelt et al., 2011). Another study in Chicago showed PSA's effectiveness to inform the people and suggested that theory-driven mass media campaign needs to be tested for public awareness (Gordon et al., 2016). Therefore, PSA and mass media should be based upon any theory or principle.

\section{Conclusion}

After considering the relevant literature compared to this study, it can be concluded that PSA is an effective strategy to improve people's knowledge and attitudes. Appropriate PSA could be able to change the behaviour of the people positively or desirably. However, PSA should include the adequate, correct and proper message to inform the people. Currently, HI's enrolment rate is not satisfactory, and on the other side, there is a high dropout rate. Therefore, presently implemented interventions need to be revised and re-evaluated since most of the interventions (PSA) did not follow HI's theoretical base for PSA. The study showed that PSA considering the constructs of HBM could increase the rate of enrollment. This strategy would be applied while doing intervention planning for the health insurance programme.

$32 \sim$ Nepalese Journal of Insurance and Social Security 


\section{Limitations}

The paper is based upon the secondary sources, i.e. PSA for HI sponsored by the HIB (formerly SHSDC). Some of the Radio/FM jingles, TV spots, message of HI in Newspaper, brochure have been changed after the endorsement of the Health Insurance Act 2017 and regulation 2019. Most of the materials were collected in 2018; therefore, new materials for PSA might be missed. PSA can be evaluated from a different perspective in this paper, PSA is assessed from the standpoint of HBM.

\section{References}

Acharya, D. (2020). Information, education, and communication for enrolment in health insurance in Nepal [Tribhuvan University]. An unpublished PhD Dissertation.

Acharya, D., Devkota, B., \& Adhikari, R. (2018). Willingness to pay for family health insurance : Evidence from Baglung and Kailali districts of Nepal. Global Journal of Health Science, 10(12), 144-155. https://doi.org/10.5539/gjhs.v10n12p144

Acharya, D., Devkota, B., Gautam, K., \& Bhattarai, R. (2020). Association of information, education, and communication with enrolment in health insurance: a case of Nepal. Archives of Public Health, 78(135), 1-13. https://doi.org/10.1186/s13690-020-00518-8

Acharya, D., Devkota, B., \& Wagle, B. P. (2019). Factors associated to the enrollment in health insurance: An experience from selected districts of Nepal. Asian Social Science, 15(2), 90-99. https://doi.org/10.5539/ass.v15n2p90

Borzekowski, D. L. G., \& Poussaint, A. F. (1999). Public service announcement perceptions: A quantitative examination of anti-violence messages. American Journal of Preventive Medicine, 17(3), 181-188.

Champion, V. L., \& Skinner, C. S. (2008). The Health Belief Model. In K. Glanz, B. K. Rimer, \& K. Viswanath (Eds.), Health behavior and health education : theory, research, and practice (4th ed., pp. 45-65). John Wiley \& Sons, Inc.

Gordon, E. J., Shand, J., \& Black, A. (2016). Google analytics of a pilot mass and social media campaign targeting Hispanics about living kidney donation. Internet Interventions, 6, 40-49. https://doi.org/10.1016/j.invent.2016.09.002

Health Insurance Act 2017, (2017). https://shs.gov.np/assets/uploads/files/Health_Insurance_Act_2074.pdf

Health Insurance Board. (2019). Annual Report: Fiscal Year 2074/75. https://hib.gov.np/public/ uploads/shares/hib_nepal_annual_report_2075_complete.pdf

Health Insurance Board. (2020). Brief Annual Report. https://hib.gov.np/public/uploads/ shares/notice_hib/health_insurance_report_2075-76.pdf

Hoffelt, Z., Fallon, S., Wong, B. A., Lucas, B., Coleman, A. L., Mills, R. P., Wilson, R., 
Volume 3 Issue 3 Dec 2020 2565-4942 (Print) 2738-9693 (online)

\& Mansberger, S. L. (2011). Glaucoma public service announcements: factors associated with follow-up of participants with risk factors for glaucoma.

Ophthalmology, 118(7), 1327-1333. https://doi.org/10.1016/j.ophtha.2010.12.013. Glaucoma

Hoffman, B. L., Cafferty, L. A., Jain, P., Shensa, A., Erica, L., Primack, B. A., \& Sidani, J. E. (2020). Patient-centered communication behaviors on Primetime Television. Journal of Health Communication, 00(00), 1-10. https://doi.org/10.1080/10810730.2020.1723040

Kepka, D., Coronado, G. D., Rodriguez, H. P., \& Thompson, B. (2011). Evaluation of a Radionovela to promote HPV vaccine awareness and knowledge among Hispanic parents. Journal of Community Health, 36, 957-965. https://doi.org/10.1007/s10900-011-9395-1

KOICA-Nepal Health Insurance Support Project [NHISP]. (2014). Comprehensive district assessment for health insurance in Kailali district.

Kreps, G. L., Yu, G., Zhao, X., Chou, S. W., \& Hesse, B. (2017). Expanding the NCI health information national trends survey from the United States to China and beyond: Examining the influences of consumer health information needs and practices on local and global health. Journalism \& Mass Communication Quarterly, 1-11. https://doi.org/10.1177/1077699016687725

Lee, M. K., Seo, J., Chu, H., Kim, H., Jang, Y. H., Jeong, J. W., Yum, H. Y., Han, M. Y., Yoon, H. J., Cho, S., Rha, Y. H., Kim, J., Park, Y. L., Seo, S. J., Lee, K. H., \& Park, C. O. (2019). Current status of patient education in the management of atopic dermatitis in Korea. Yonsei Medical Journal, 60(7), 694-699. https://doi.org/10.3349/ymj.2019.60.7.694

Liem, S., Marta, R. F., \& Panggabean, H. (2019). Sanitation behavior and risk of stunting: Understanding the discourse of a public service announcement. Jurnal The Messenger, 11(2), 168-181. https://doi.org/10.26623/themessenger.v11i2.1317

Macy, J. T., Chassin, L., Presson, C. C., \& Sherman, J. W. (2015). Changing implicit attitudes toward smoking: Results from a web-based approach-avoidance practice intervention. Journal of Bhavioral Medicine, 38(1), 143-152. https://doi.org/10.1007/s10865-014-9585-2

Maidin, A., Sakrani, S. N. R., Wahab, S. A., \& Razak, N. A. A. (2019). Public service announcement by government through social media: A public's perspective. International Journal of Heritage, Art and Multimedia, 2(4), 1-11.

Health Insurance Act, 1 (2017). http://www.lawcommission.gov.np/np/archives/24220 Ministry of Finance. (2020). Economic Survey 2076/77. Kathmandu, Nepal Ministry of Health and Population (MOHP) [Nepal], New ERA, \& ICF International Inc. (2012). Nepal Demographic and Health Survey 2011. https://dhsprogram.com/ 
pubs/pdf/FR257/FR257\%5B13April2012\%5D.pdf

Ministry of Health and Population (MOHP) [Nepal], New ERA, \& Macro International Inc. (2007). Nepal Demographic and Health Survey 2006. https://dhsprogram.com/pubs/pdf/FR191/FR191.pdf

Ministry of Health, New ERA, \& ICF. (2017). Nepal Demographic and Health Survey 2016. www.dhsprogram.com/pubs/pdf/fr336/fr336.pdf

Murry, J. P. J., Stam, A., \& Lastovicka, J. L. (1996). Paid versus donated media strategies for public service announcement campaigns. Public Opinion Quarterly, 60, 1-29.

Nan, X. (2008). The influence of liking for a public service announcement on issue attitude. Communication Research, 35(4), 503-528. https://doi.org/10.1177/0093650208316053

Health insurance regulations, 2075, 1 (2019). https://hib.gov.np/public/uploads/shares /nimabali.pdf

Rydell, R. J., Sherman, S. J., Boucher, K. L., \& Macy, J. T. (2013). The role of motivational and persuasive message factors in changing implicit attitudes toward smoking. Basic and Applied Social Psychology, 34(1), 1-12. https://doi.org/10.1080/01973533.2011.637847

Subedi, L., Regmi, M. C., \& Giri, Y. (2018). Assessment of community based health insurance in Sunsari District. Kathmandu University Medical Journal, 16(61), 5359. http://www.kumj.com.np/issue/61/53-59.pdf

Ti, L., Fast, D., Small, W., \& Kerr, T. (2017). Perceptions of a drug prevention public service announcement campaign among street-involved youth in Vancouver, Canada: A qualitative study. Harm Reduction Journal, 14(3), 1-8. https://doi.org/10.1186/s12954-017-0132-7

Toncar, M., Reid, J. S., \& Anderson, C. E. (2007). Effective spokespersons in a public service announcement. Journal of Communication Management, 11(3), 258-275. https://doi.org/10.1108/13632540710780247

Weber, R., Westcott-Baker, A., \& Anderson, G. (2013). A multilevel analysis of antimarijuana public service announcement effectiveness. Communication Monographs, 80(3), 302-330. https://doi.org/10.1080/03637751.2013.788254

White, H. A., \& Dillon, J. F. (2000). Knowledge about other's reaction to a public service announcement: The impact of self persuasion and third-person perception. Journalism \& Mass Communication Quarterly, 77(4), 788-803.

Won, K., Lee, J., Ryu, J., \& Jeong, S. (2017). Effects of Anti-Smoking Public Service Announcements on the Attitudes of Korean College Students toward Smoking. Osong Public Health and Research Perspectives, 8(6), 397-403. https://doi.org/10.24171/j.phrp.2017.8.6.07 
Volume 3 Issue $3 \quad$ Dec 2020 2565-4942 (Print) 2738-9693 (online)

\section{Appendix I}

\section{Television Messages}

Message of Rajesh Hamal....[https://www.youtube.com/watch?v=S7iZnO7bftI]

Message of Yamraj..... [https://www.youtube.com/watch?v=AxwJ605S-bE]

Message of Suntali Dhurmus...[https://www.youtube.com/watch?v=gN4yWo_jxYg]

Message of Jigri-Pande...[https://www.youtube.com/watch?v=5wmARgqcH54]

Message of Dr Koirala....[https://www.youtube.com/watch?v=TrI8bMY9nrY]

Mother-Son Talking from aboard....[https://www.youtube.com/watch?v=Hxqoqt-xj5U]

Message of Pashupati's song ...[https://www.youtube.com/watch?v=zywZI3bh-kU]

Message of couple/husband-wife talking...[https://www.youtube.com/watch?v=OPR9y8PIDqQ] 